\title{
The Performance Analysis of Artificial Neural Network Based Shimizu-Morioka Chaotic System with Respect to Sample Numbers
}

\author{
M. Alçın, I. Pehlivan, and I. Koyuncu
}

\begin{abstract}
In this paper, Shimizu-Morioka Chaotic System (SMCS) is modelled using Feed Forward Artificial Neural Network. In the realized network model, Log-Sigmoid and Purelin transfer functions have been used for hidden and output layer, respectively. 3-10-3 network structure is created using MATLAB. The model inputs are the state variables of SMCS. Outputs represent not only the outputs of SMCS but also iterative versions of these inputs. For the equations' numeric solutions of describing SMCS, Runge Kutta 5 Butcher (RK-5-B) algorithm which is one of the differential equation solution methods, is used. Samples in the structure of described network, the created different numbers of samples using RK-5-B have been used as input data and performance analysis have been performed for these data. As a result, the paper shows that when the sample data numbers increase, network modeling performance gives more successful results.
\end{abstract}

Index Terms-Artificial Neural Networks, Chaotic System, Numerical Algorithm, Modeling.

\section{INTRODUCTION}

$\mathrm{C}$ HAOS has attracted the attention of scientists who work on nonlinear systems in recent years. Communication systems have become one of the most commonly used areas of chaos in engineering applications. Chaotic oscillators have frequently been used for the construction of such systems. There has been many researches exploiting chaotic oscillators in the areas of control, prediction, optimization, energy, cryptology and nanotechnology.

Artificial Neural Network (ANN) is a complex system in Artificial Intelligence (AI) that simulates human brain capabilities such as learning and generalization. It is possible to use ANN in function estimation, classification, pattern recognition, signal processing and system modeling.

M. Alçın is with Anadolu University, Porsuk Vocational School, Department of Electrical-Energy, Eskişehir, 26470, Turkey, (e-mail: muratalcin@anadolu.edu.tr).

I. Pehlivan is with Sakarya University, Department of Electrical and Electronics Engineering, Sakarya 54187, Turkey, (e-mail: ipehlivan@sakarya.edu.tr).

I. Koyuncu is with Duzce University, Duzce Vocational School, Department of Electronics and Automation, Duzce, 81100, Turkey, (e-mail: ismailkoyuncu@duzce.edu.tr).
ANN have recently been used in many fields like prediction $[1,2]$, classification [3, 4], control [5, 6], optimization [7, 8], the analysis of complex problems and modeling of nonlinear systems $[9,10]$. The usage of ANN in modeling of nonlinear systems has an important role in modeling chaotic oscillators using ANN. In the present work, the modeling of ShimizuMorioka Chaotic System (SMCS) using Feed Forward Neural Network (FFNN) is presented [11-13]. For the numeric solution of the system, Runge Kutta 5 Butcher (RK-5-B) algorithm which is one of the differential equation solution methods is used [14]. A detailed analysis of the modeling related to sample number is carried out and obtained results have been explained.

\section{BACKGROUND INFORMATION}

\section{A. Artificial Neural Networks}

Nowadays, Fuzzy-Logic, Genetic Algorithms and ANN are among the AI technics that have been used in various areas [10, 15]. ANN can be used not only in system identification but also in modeling of system. Artificial Neuron system can be performed in modeling and analyzing of chaotic systems with a great success [9]. Model structure of feed-forward ANN for SMCS was shown in Fig. 1.

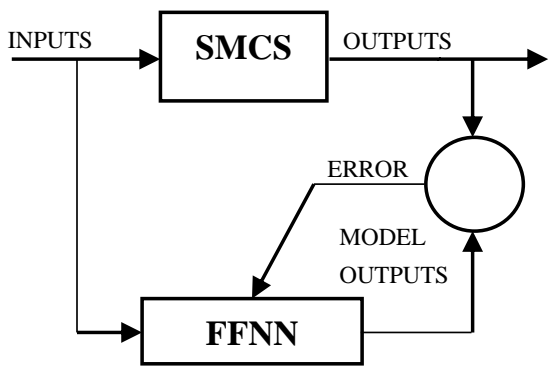

Fig. 1. Model structure of Feed-Forward ANN for SMCS.

ANN consists of inter-connected neurons which are organized in the form of layers [9]. The basic processing element of ANN is called artificial neuron (AN) as shown in Fig. 2. The ANN given in this figure has an input, denoted as $\mathrm{p}$. The line connecting this input to the neuron is assigned a weight, denoted as $w$. 
The neuron also includes an externally applied bias, denoted by $\mathrm{b}_{\mathrm{k}}$. The activation, $f$, determines whether the neuron is to be fired or not [16].

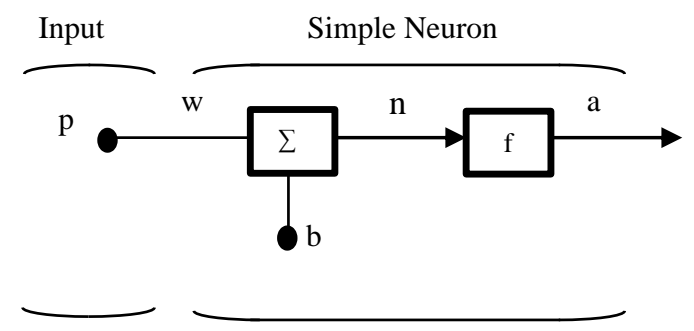

Fig. 2. Simple Neuron Structure [15].

This neuron has 3 functional operations. Firstly, $p$ is multiplied with $\mathrm{w}$ to produce weighted input, denoted as wp in (1).

$$
w p=w \cdot p
$$

Then, weighted input is summed with bias, denoted by $b$ to produce net input, denoted by $n$ in (2).

$$
n=w \cdot p+b
$$

Finally, the net output, denoted by $a$ is obtained by applying transfer function to $n$. These three steps are called weight function, net input function and transfer function [10, 17]. There are various transfer functions used in neuron structure in literature [18]. The neuron output, $a$ is given in (3)

$$
a=f(w p+b)
$$

\section{B. Shimizu-Morioka Chaotic System}

Shimizu-Morioka Chaotic System is defined by the simple three-dimensional autonomous system in (4) [11]. T. Shimizu and N. Morioka have found out this system by computer simulations in 1980.

$$
\begin{aligned}
& \dot{x}=y \\
& \dot{y}=x-a \cdot y-x \cdot z \\
& z=-b \cdot z+x^{2}
\end{aligned}
$$

$\mathrm{a}=0.85$ and $\mathrm{b}=0.5$ are the system pparameters of the SMCS. $\mathrm{x}_{0}=0.1, \mathrm{y}_{0}=0.1$, and $\mathrm{z}_{0}=0.1$ are the initial conditions of SMCS. The chaotic attractors obtained from these conditions using MATLAB software were given in Fig. 3.

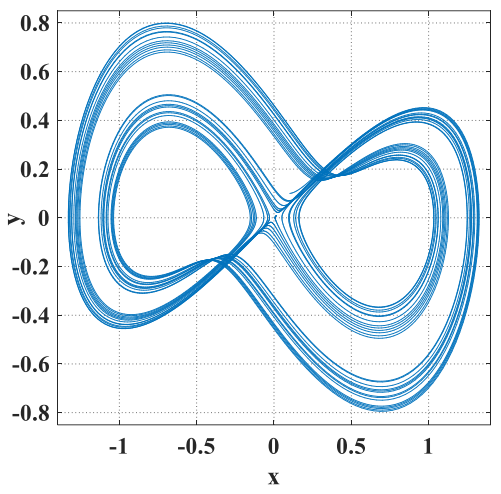

(a)

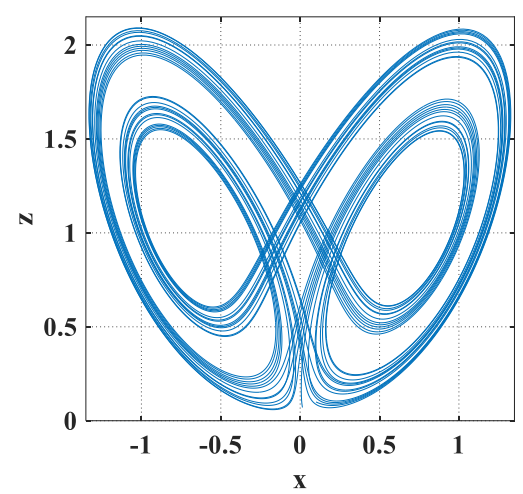

(b)

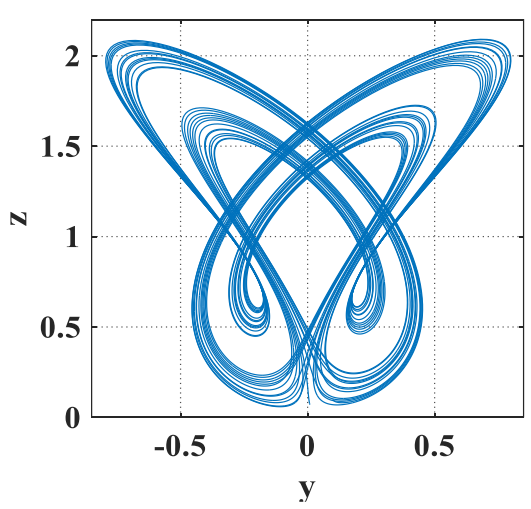

(c)

Fig. 3. The chaotic attractors of the Shimizu-Morioka Chaotic System for initial conditions $\mathrm{x}_{0}=0.1, \mathrm{y}_{0}=0.1, \mathrm{z}_{0}=0.1$ and system parameters $\mathrm{a}=085$ and $\mathrm{b}=0.5$, a) $x-y$ chaotic attractors, b) $x-z$ chaotic attractors and c) $y-z$ chaotic attractor.

\section{MODELING OF THE SHIMIZU-MORIOKA CHAOTIC SYSTEM}

In this paper, Shimizu-Morioka Chaotic System has been modeled using FFNN having different data sets of 100, 1000 and 10000 sample numbers. In the structure of modeled network, inputs represent the state variables and outputs represent the iterative versions of these inputs. As can be seen in Fig. 4, input layer has 3 inputs and output layer has 3 outputs. There are 10 neurons in hidden layer. LoSig (Logistic Sigmoid) transfer function has been used in hidden layer and Purelin transfer function has been used in output layer. 


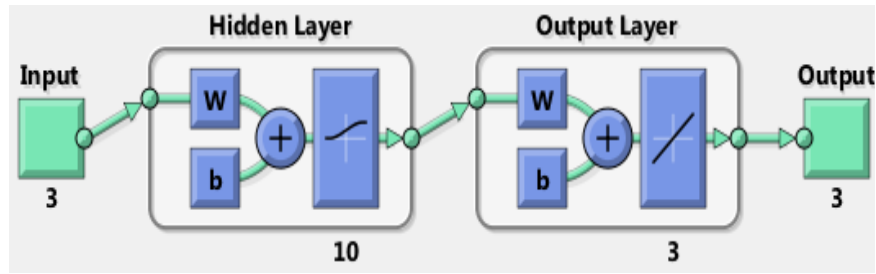

Fig. 4. View of ANN-based Shimizu-Morioka Chaotic System in MATLAB.

The parameters related to ANN-based Shimizu-Morioka Chaotic System has been given in Table I.

TABLE I

MODEL PARAMETERS

\begin{tabular}{lc}
\hline \hline \multicolumn{2}{c}{ FFNN Model Structure } \\
\hline Number of layers & 3 \\
Number of neurons in layers & Input: 3 Hidden:10 Output:3 \\
$\begin{array}{l}\text { Initial weights and bias values } \\
\text { Transfer Function }\end{array}$ & Random \\
Learning Rule & Hidden:Log-Sigmoid Output:Linear \\
\hline \hline
\end{tabular}

\section{PERFORMANCE RESUlts OF FFNN BASED SMCS}

In this work, it is clear to see that the SMCS has been successfully modeled for three different data sets. The performance results related to training have been presented in Fig. 5, Fig. 6 and Fig. 7.

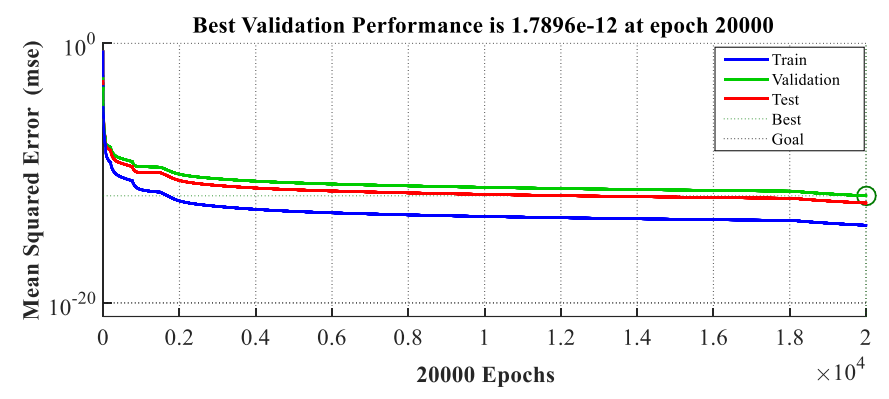

Fig. 5. Network performance results for data set of 100 samples.

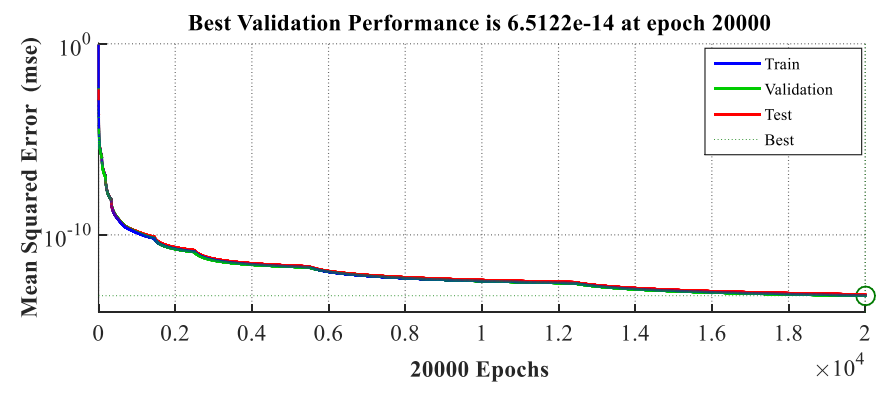

Fig. 6. Network performance results for data set of 1000 samples.

TABLE II

ANALYSIS OF MEAN SQUARE ERROR

\begin{tabular}{cccc}
\hline \hline & 100 sample & 1000 sample & 10000 sample \\
\hline Mean Square Error (MSE) & $1.7896 \mathrm{e}-12$ & $6.5122 \mathrm{e}-14$ & $1.2622 \mathrm{e}-14$ \\
\hline \hline
\end{tabular}

Mean Square Error (MSE) has been decreasing collaterally for each of training, validation and test data. Furthermore, the analysis results of MSE has been given in Table II.

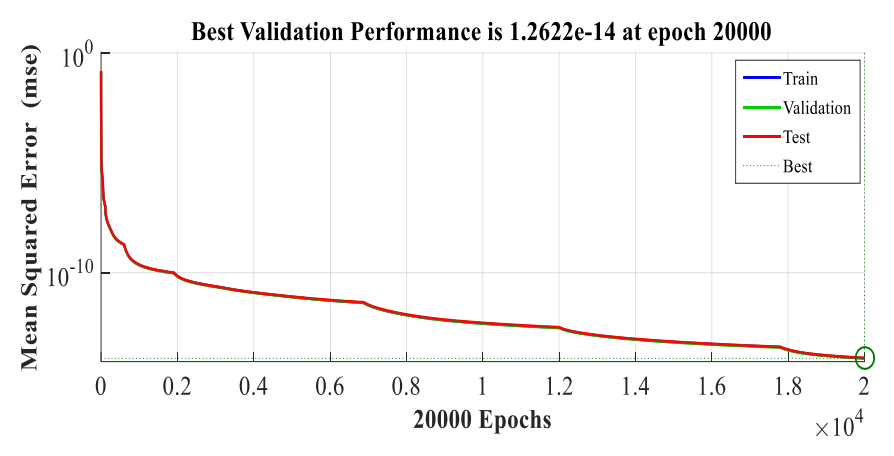

Fig. 7. Network performance results for data set of 10000 samples.

\section{CONCLUSIONS}

This paper presents the analysis of modeling performance effect of the network with respect to ANN model and sample data number to be used for modeling the dynamics of ShimizuMorioka Chaotic System. The numeric solutions of the equations describing the SMCS have been performed with RK5-B algorithm. The obtained data sets having sample numbers of 100, 1000 and 10000 have been modeled by FFNN separately for the network parameters. The performance results have been presented for each of the data sets. As a result, it is seen that the increment of sample number has a positive effect on the modelling performance. In other words, when the sample number increases, the Mean Square Error will decrease.

\section{ACKNOWLEDGMENT}

The study is selected from National Engineering Research Symposium 2015 (Ulusal Mühendislik Araştırmaları Sempozyumu) UMAS 2015 (Duzce University).

\section{REFERENCES}

[1] R. Adhikari, "A neural network based linear ensemble framework for time series forecasting", Neurocomputing, Elsevier, vol. 157, pp. 231-242, 2015.

[2] C. U. Vila, A. C. Z. Souza, J. W. M. Lima, and P. P. Balestrassi, "Electricity demand and spot price forecasting using evolutionary computation combined with chaotic nonlinear dynamic model", Electrical Power and Energy Systems, vol. 32, pp. 108-116, 2010.

[3] Q. Nie, L. Jin, S. Fei, and J. Ma, "Neural network for multiclassclassification by boosting composite stumps", Neurocomputing, vol. 149, pp. 949-956, 2015.

[4] A. J. Hussain, P. Fergus, H. Al-Askar, D. Al-Jumeily, and F. Jager, "Dynamic neural network architecture inspired by the immune algorithm to predict preterm deliveries in pregnant women", Neurocomputing, vol. 151, pp. 963-974, 2015.

[5] V. Kumar, P. Gaur, and A. P. Mittal, "ANN based self tuned PID like adaptive controller design for high performance PMSM position control", Expert Systems with Applications, vol. 41, pp. 7995-8002, 2014.

[6] M. M. Noel, and B. J. Pandian, "Control of a nonlinear liquid level system using a new artificial neural network based reinforcement learning approach", Applied Soft Computing, vol. 23, pp. 444-451, 2014. 
[7] G. Das, P. K. Pattnaik, and S. K. Padhy, "Artificial Neural Network trained by Particle Swarm Optimization for non-linear channel equalization", Expert Systems with Applications, vol. 41, pp. 3491-3496, 2014.

[8] J. D. Pintér, "Calibrating artificial neural networks by global optimization", Expert Systems with Applications, vol. 39, pp. 25-32, 2012.

[9] R. Archana, A. Unnikrishnan, and R. Gopikakumari, "An Improved EKF based neural network training algorithm for the identification of chaotic systems driven by time series", 2012 IEEE International Conference on Power, Signals, Controls and Computation (EPSCICON), 2012.

[10] H. Altınkaya, İ. M. Orak, and İ. Esen, "Artificial neural network application for modeling the rail rolling process", Expert Systems with Applications, vol. 41, pp. 7135-7146, 2014.

[11] M. M. El-Dessoky, M. T. Yassen, and E. S. Aly, "Bifurcation analysis and chaos control in Shimizu-Morioka chaotic system with delayed feedback, Applied Mathematics and Computation”, vol. 243, pp. 283297, 2014

[12] X. Liao, F. Xu, P. Wang, and P. Yu, "Chaos control and synchronization for a special generalized Lorenz canonical system - The SM system", Chaos, Solitons and Fractals, vol. 39, pp. 2491-2508, 2009.

[13] S. Yu, W. K. S. Tang, J. Lü, and G. Chen, "Generation of nxm-Wing Lorenz-Like Attractors From a Modified Shimizu-Morioka Model", IEEE Transactıons On Circuits And Systems-II: Express Briefs, vol. 55(11), 2008.

[14] C. Tsitouras, Runge-Kutta pairs of order 5(4) satisfying only the first column simplifying assumption, Computers and Mathematics with Applications, vol. 62, pp. 770-775, 2011.

[15] M. Tuna, C. B. Fidan, S. Kocabey, and S. Görgülü, "Effective and Reliable Speed Control of Permanent Magnet DC (PMDC) Motor under Variable Loads", Journal of Electrical Engineering \& Technology, vol. 10(5), pp. 2170-2178, 2015.

[16] M. H. Beale, M. T. Hagan, and H. B. Demuth, "The Neural Network Toolbox User's Guide R2014b”, The MathWorks, 2015.

[17] Mohammed, E.Z., and Ali, H.K. "Hardware Implementation of Artificial Neural Network Using Field Programmable Gate Array", International Journal of Computer Theory and Engineering, 5(5), 780-783, 2013.

[18] Sahin, I., and I. Koyuncu. "Design and Implementation of Neural Networks Neurons with RadBas, LogSig, and TanSig Activation Functions on FPGA", Electronics and Electrical Engineering, vol. 120(4), pp. 51-54, 2012.

\section{BIOGRAPHIES}

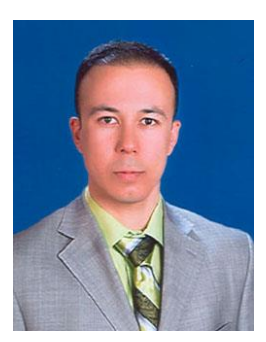

Murat ALCIN was born in Esence Village, Eskisehir, in 1982. He received the B.S. and M.S. degrees in Electronic-Computer Teaching from the University of Marmara, Turkey, in 2006 and in 2009, respectively. Receiving his doctoral research in the Department of Electrical and Electronics Engineering at Sakarya University, in Sakarya-Turkey. He is a research assistant in Anadolu University Electric-Energy Department in Porsuk Vocational School, EskisehirTurkey. From 2006 to 2008, he was a teacher in Simav Anatolian Vocational High School in Kutahya. From 2008 to 2012, he was an instructor in Abant İzzet Baysal University Electronic Technology Program at Bolu Vocational School, Bolu-Turkey. From 2012 to 2014, he was an instructor in Osmangazi University Compter Programming Program at Sivrihisar Vocational School, Eskisehir-Turkey. Since 2014, he has been a Research Assistant with the Electric-Energy Department, Eskisehir Anadolu University. His research interests include Neural Networks, Chaotic Systems and FPGA-based digital system design.

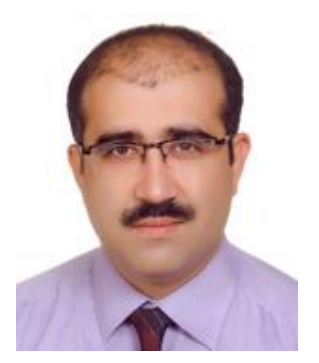

Ihsan PEHLIVAN received the B.S. from Istanbul Technical University in 1997, M.S. and $\mathrm{PhD}$ degrees in 2001 and 2007 respectively in Electrical-Electronic Engineering from Sakarya University, Sakarya-Turkey. He is an Associated Professor in the Department of Electrical and Electronics Engineering at Sakarya University, in Sakarya-Turkey. He is the author of a book, more than 30 articles. His research interests include chaos, electric circuits and signals-system.

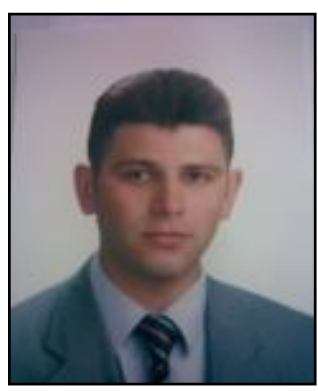

Ismail KOYUNCU has an M.S. from Abant Izzet Baysal University, Bolu-Turkey. He is currently conducting his doctoral research in the Department of Electrical and Electronics Engineering at Sakarya University, SakaryaTurkey. He is an instructor in Duzce University Control and Automation Technology Program at Duzce Vocational High School, Duzce-Turkey. His main research interests are FPGA-based digital system design, neural networks, and reconfigurable computing. He is also interested in chaos and computer graphics. 